\title{
Modelling water pollution posing a risk to human and ecosystem health in Africa using FC and BOD as indicator substances
}

\author{
K. Reder ${ }^{1}$, M. Malsy ${ }^{1}$, I. Bärlund ${ }^{2}$ \& M. Flörke ${ }^{1}$ \\ ${ }^{1}$ Center for Environmental Systems Research, \\ University of Kassel, Germany \\ ${ }^{2}$ Helmholtz Centre for Environmental Research UFZ, Germany
}

\begin{abstract}
African water quality is for large parts of the continent unknown, as very little measured data exists. To gain insight into African water quality, which affects humans and ecosystems, a simulation approach with the large-scale model WorldQual was applied. Simulations were carried out for the year 2010 for faecal coliform (FC) bacteria and for the year 2009 for biological oxygen demand (BOD). Results show regions with high loadings and in-stream concentrations (hotspot regions) at the coastline of Morocco, Algeria and Tunisia, Eastern Africa, parts of Western Africa, and the east of the Republic of South Africa. Main contributors of loads are the domestic sector (48.5\%) for FC and manure application (52.5\%) for BOD. In a further model experiment it was investigated how loadings and in-stream concentrations change, assuming the whole population is connected to sewage systems without any improvement of treatment levels. Model results show a substantial increase of current hotspots and in-stream concentrations which are likely to double in extent. These findings highlight that management strategies to improve sanitation disposal and thus in turn water quality have to consider that not only a functioning sewage system has to be ensured but also the treatment of the generated wastewater.

Keywords: large-scale, modelling, Africa, loadings, in-stream concentrations, human health, ecosystem health, faecal coliform bacteria, biological oxygen demand, water quality.
\end{abstract}




\section{Introduction}

The Millennium Development Goals [1] reach out to reduce poverty, keep or develop peace and ensure environmental sustainability. This includes reducing by half the population without access to improved sanitation until 2015 (goal 7, target 10) [2]. But in 2011 in developing countries still 2.6 billion people (29\%) lacked access to improved sanitation [3], and in Africa 34\% of the population practiced open defecation [4]. The lack of sanitation degrades freshwater quality which in turn poses a severe threat to human and ecosystem health, food security and the economy.

Africa's current and projected demographic changes lead to high levels of population growth and urbanization. It is assumed that $57.7 \%$ of all Africans will be living in urban areas in 2050, whereas it was 39.6\% in 2011 [5]. The expected demographic trends are important drivers of economic growth [6]; however, the infrastructure in developing countries does not grow at the same pace as demographic change and urbanization, which increases the risk of water degradation [7]. It is hypothesized that the infrastructure of sewage systems is developing, but little progress is made in improving treatment rates and levels. This results in higher pollution of freshwater systems as the wastewaters are directly discharged into the rivers without treatment.

To measure and assess the threat to human and ecosystem health, indicator substances are frequently used. This includes faecal coliform (FC) bacteria as a measure of pathogen contamination and internationally accepted indicator for human health [8,9]. Biological oxygen demand (BOD) is an indicator for ecosystem health by measuring the organic pollution and efficiency of sewage treatment plants.

In order to tackle water quality problems in Africa, first the water quality problems have to be identified. Because Africa is a very data scarce region and monitoring is rare, water quality models can be applied to support the identification and analysis of regional hotspots. Model results provide information on loadings and in-stream concentration patterns which show hotspot regions, i.e. regions where loadings or in-stream concentrations are high (or both) and exceed e.g. guidelines for water used for irrigation.

The objective of this study is to identify and evaluate hotspots of water pollution posing a threat to human and ecosystem health in Africa. Simulations are carried out with the large-scale water quality model WorldQual for the years 2009 and 2010. Resulting loading and in-stream concentration patterns of BOD and FC are overlaid to highlight hotspot regions. Furthermore, the impact of changes in sanitation practices is analysed under the assumption that the total population is connected to a sewage system but treatment rates and levels are the same as under current conditions. 


\section{Methods}

\subsection{Model description}

WorldQual is a large-scale water quality model developed to simulate biological oxygen demand (BOD), faecal coliform bacteria (FC), total nitrogen (TN), total phosphorus (TP), and total dissolved solids (TDS). These substances have successfully been simulated and validated at the European scale [10-14]. The model operates on monthly time steps and a spatial 5 by 5 arc-minute grid resolution ( $\sim 9$ by $9 \mathrm{~km}$ at the equator). Model results are pollutant loadings and in-stream concentrations. Loadings are calculated separately for point sources and diffuse sources (fig. 1) where point sources include domestic sewage, wastewater from manufacturing industries, and urban surface runoff. Diffuse sources comprise agricultural inputs such as organic fertilizer (manure application), industrial fertilizer, and geogenic background emissions. Additionally, scattered settlements are considered as point and diffuse sources, depending on the type of sewage disposal the input is a diffuse (e.g. open defecation) or point source (e.g. hanging latrines).

A detailed description of the estimation of the different point source loadings is provided by Williams et al. [14]. The domestic loads from sewage are calculated by multiplying a per capita emission factor by the urban and rural population connected to sewage treatment plants (STPs). The load reaching STPs is reduced depending on the treatment level, i.e. national values for primary, secondary and tertiary treatment. Loadings from urban surface runoff are calculated by multiplying the typical event mean concentration by the urban surface runoff. The loads resulting from manufacturing are estimated by multiplying the average raw effluent concentration by the return flow from manufacturing industries.

Diffuse loadings are estimated from organic and industrial fertilizers and geogenic background loads. Loads from organic fertilizer (manure application) are calculated by multiplying the load of a pollutant in manure by a substance specific release rate and the respective surface runoff [12]. For BOD, loads from industrial fertilizer are calculated by multiplying the typical pollutant concentration in the surface runoff from cropland by the surface runoff and the agricultural (unsealed) area of the cell. Industrial fertilizers do not contain faecal coliform bacteria. Little or no information on geogenic background emissions for FC or BOD is available. Furthermore, the share of geogenic background loads of the total load is supposed to be small and is therefore not considered for FC and BOD estimates.

Scattered settlements contain the loads from the population not connected to STPs. In order to distinguish between different ways of sanitary waste disposal in scattered settlements, three classes were established (fig. 1): i) Scattered settlements with some type of private onsite disposal, such as septic tanks, pit toilets, bucket latrines etc. Here the load is calculated like the domestic loads, by multiplying a per capita emission factor by the population connected to these disposal types. The load is reduced by a reduction factor which includes decay 
processes and the percentage of leakages. This class can either be a point or diffuse input. ii) Scattered settlements where people practice open defecation are calculated analogue to loads from manure application by multiplying the load of a pollutant in human faeces by a substance specific release rate and the respective surface runoff. This class is regarded as diffuse input. iii) Scattered settlements with hanging latrines are calculated by multiplying the per-capita load by a per-capita emission factor. No reduction takes place as the faeces are directly disposed into the surface waters, therefore, this class is considered as point input.

The estimated cell-specific pollutant loads are divided by the river discharge of each grid cell to generate the in-stream concentration. Additionally, the instream concentration of an upstream cell is routed into the next downstream grid cell following a high-resolution drainage direction map [15]. Substance-specific and temperature-dependent decay processes reduce the in-stream concentration within a grid cell [16]. Furthermore, FC in-stream concentrations are reduced by decay due to solar radiation and sedimentation [16].

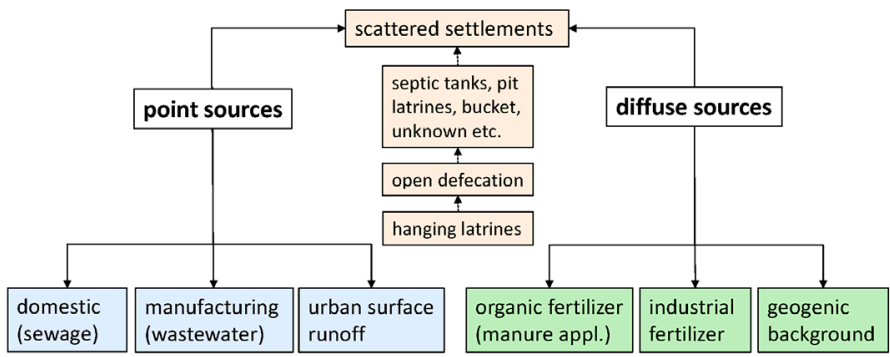

Figure 1: Sectors contributing to point and diffuse sources to calculate loadings in WorldQual.

WorldQual is a module of the modelling framework Water Global Assessment and Prognosis (WaterGAP3) which furthermore consists of hydrology and water use models. The hydrology model operates on a 5 by 5 arcminute grid in daily time steps [17] and is a further development of WaterGAP2 $[18,19]$. On the basis of climate time series (air temperature, precipitation, and solar radiation) a daily water balance is computed for each grid cell. Regarding water use, abstractions and consumption are calculated for the domestic, manufacturing, thermal electricity production, irrigation, and livestock sectors $[18,20,21]$. This integrated approach feeds sectoral water abstractions into the hydrological module to simulate anthropogenic effects on natural water resources.

\subsection{Modelling water quality}

Simulations are carried out for the reference year 2010 for FC and 2009 for BOD because these are the most recent years for which observations as well as climate 
input is available. In terms of FC, a validation dataset was provided by the South African Department of Water Affairs for 2010, while for BOD the data were made available by the United Nations Global Environment Monitoring System (GEMS) Water Programme. Here we used the latest BOD in-stream concentrations measured at stations located in Morocco for 2009. In a further model experiment we assumed that the whole population is connected to a sewer system, but the percentage of the population connected to primary, secondary and tertiary treatment remains the same as in the baseline simulation. Regional hotspots were identified by high loadings or in-stream concentrations, e.g. for FC high loadings are loadings which exceed guidelines of water useable for irrigation.

\section{Results and discussion}

\subsection{Model evaluation}

Simulated in-stream concentrations are validated against measured in-stream concentrations for each substance. FC in-stream concentrations are analysed at the Mhlatuze River in the Republic of South Africa (fig. 2). Overall, the simulated in-stream concentrations show less variation compared to the measured time series. Because of the low variation, the simulated FC concentration overestimates the low concentrations measured during the year and underestimates the high concentration values. The simulated in-stream

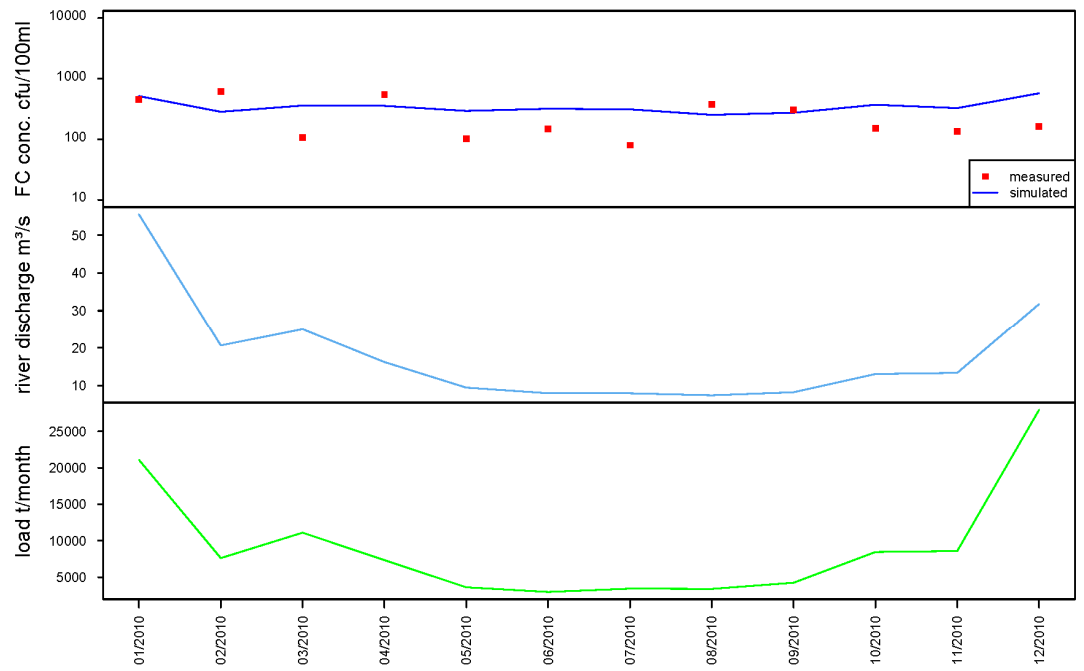

Figure 2: Mhlatuze River, Republic of South Africa from January to December 2010; (top): simulated vs. measured FC in-stream concentrations; (middle): river discharge; (bottom): calculated load reaching the Mhlatuze River. 
concentrations show some variation between January and February and October to December as a result of the loadings which increase by $>5.000 \mathrm{t} / \mathrm{month}$. Overall, the impact of loadings on the in-stream concentration is higher than the river discharge because the in-stream concentration follows the trend of the loadings e.g. drops in February. This is contrary to the influence of the river discharge which would lead to higher in-stream concentrations in February due to reduced dilution capacity. The intra-annual variability of loadings and river discharge is similar and clearly affected by precipitation. The load is mostly influenced by the manure application (67\% of the total load) at this station, which varies according to the surface runoff in each month. High precipitation events induce high surface runoff, which in turn increases the amount of FC to be released from the applied manure. At the same time river discharge increases as a consequence of precipitation.

To analyse BOD in-stream concentrations the Oum Er-Rbia River in central Morocco was selected (fig. 3). The simulated in-stream concentrations follow the dynamic and magnitude of the measured in-stream concentrations from April to December. From September to December the simulated in-stream concentrations slightly overestimate the measured in-stream concentrations. The dynamic and magnitude is not met in the first three months of the year, where the measured in-stream concentration shows a steep increase. In February 2009 the load quadrupled but at the same time the river discharge also increases. Contrary to the effect of loadings and river discharge on FC in-stream concentrations, the river discharge has larger impact on BOD in-stream concentrations than the

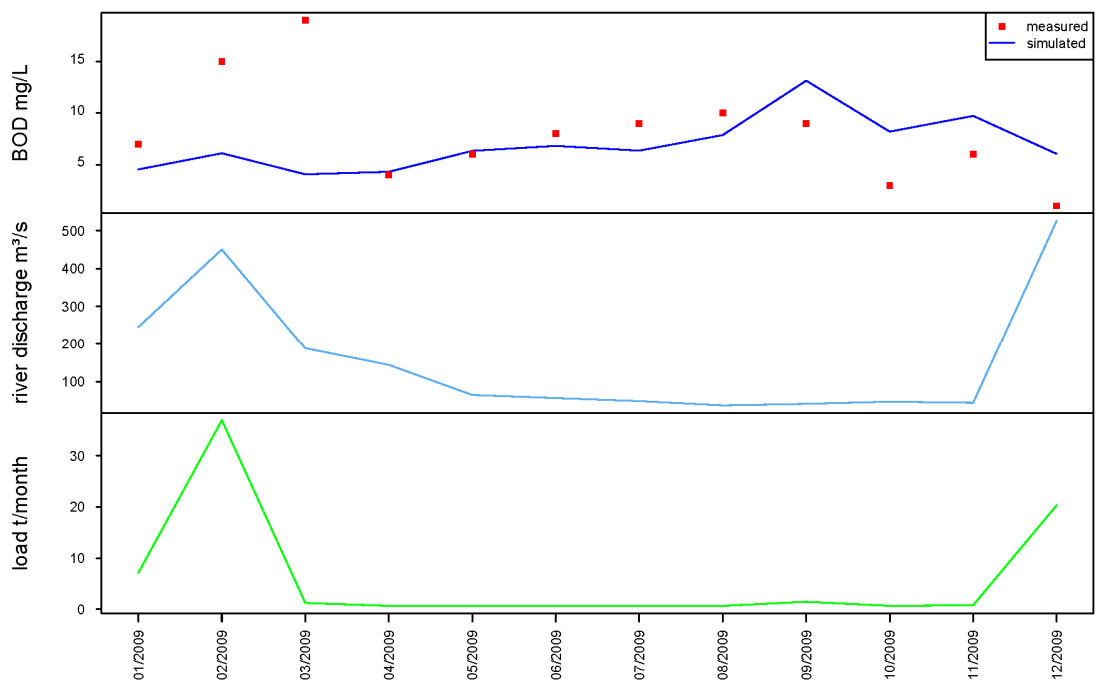

Figure 3: Oum Er-Rbia River from January to December 2009; (top): simulated vs. measured BOD in-stream concentrations (middle): river discharge; (bottom): calculated load reaching the Oum Er-Rbia River. 
BOD load. Thus the modelled BOD in-stream concentration only slightly increases in February. In March the measured in-stream concentration is very high but the simulated in-stream concentration is low which is due to low loadings and a medium river discharge. The monthly variation of the loadings is induced by the variation of surface runoff on manure application, open defecation and the urban surface runoff. Here no retention is implemented in the model equations hence at a high surface runoff event the resulting high loadings will only be attributed to the month with the high surface runoff. In further research retention of the surface runoff can be included in WorldQual.

\subsection{Loading hotspots}

To detect patterns of high and low FC and BOD loadings in Africa the loadings are classified into high, medium and low (tab. 1).

Table 1: Range of high, medium and low loadings for FC $10^{10} \mathrm{cfu} \mathrm{km}^{-2} \mathrm{a}^{-1}$ and BOD kg km $\mathrm{ka}^{-2}$.

\begin{tabular}{lccc}
\hline Substance & Low & Medium & High \\
\hline FC & $0-500$ & $500-1000$ & $>1000$ \\
BOD & $0-10$ & $10-100$ & $>100$ \\
\hline
\end{tabular}

Figure 4a) illustrates pattern of loading hotspots in Africa by combining the maps of FC and BOD loadings. Regions where FC and BOD loadings are high pose a potential threat to human and ecosystem health. These regions include the coastline of Morocco, Algeria and Tunisia, the Nile catchment, Western Africa, Eastern Africa, western Angola, and the eastern part of the Republic of South Africa. Low FC and BOD loadings are visible in the Sahara and Middle Africa. Opposed loadings, i.e. high BOD and low FC loadings, are in Somalia and western Ethiopia, southern Sahara and South-east Africa. This results from the distribution of loads from the domestic sector and manure application, which are the major contributors of FC and BOD loads. The pattern of both substances is similar, nevertheless different in these regions, e.g. in Somalia, the domestic sector mainly contributes to the total FC load whereas manure application leads to the high BOD loads.

In category high + high $(\mathrm{HH})$ are $21 \%$ of the total African land area and $85 \%$ of the African population lives in these hotspot regions. Assuming that $\mathrm{HH}$ and medium + high $(\mathrm{MH})$ are hotspot regions then $36 \%$ of the African land area and even $93 \%$ of the African population lives in hotspot regions.

In a further model experiment it is assumed that the total African population is connected to sewage systems but the treatment rates and levels remain the same as in the reference year. Results of this model experiment are presented in figure $4 \mathrm{~b}$ ) analogue to figure 4a) for the reference year. High loadings are apparent in almost all sub-Saharan Africa and along the northern African coast, except the Sahara and western parts of Southern Africa. The area in category low 
+ high (LH) is very small. The regions with LH are in north Sudan, south Tunisia and small parts of south western Angola and north-east of the Republic of South Africa. Here BOD loads are high due to organic and inorganic fertilizer and FC load is low. Compared to the reference year, areas with $\mathrm{MH}$ turned into $\mathrm{HH}$ just as most of $\mathrm{LH}$ areas. According to the results obtained in the model experiment, Africa is divided into low +low (LL) and $\mathrm{HH}$ areas while less area can be found in the other classes. Therefore, this model experiment shows areas at possible risk of high pollution and areas at low risk, respectively. The area of $\mathrm{HH}$ accounts for $52 \%$ of the total African land area. This is more than twice as much as the area in $\mathrm{HH}$ for the reference year. $59 \%$ of the total African area is in the categories $\mathrm{HH}$ and $\mathrm{MH}$, indicating the small proportion of $\mathrm{MH}(7 \%)$. Regarding the population living in the area classified as $\mathrm{HH}$ or $\mathrm{HH}$ and $\mathrm{MH}$ is $98 \%$ or $99 \%$, respectively. Furthermore, $50 \%$ to $60 \%$ of the African land area can be identified as hotspot regions, which means that the ecosystems located in these regions, are at risk as well as the majority of the African population.

a)

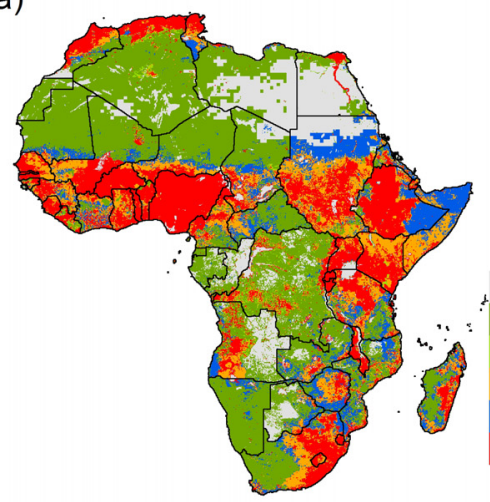

b)

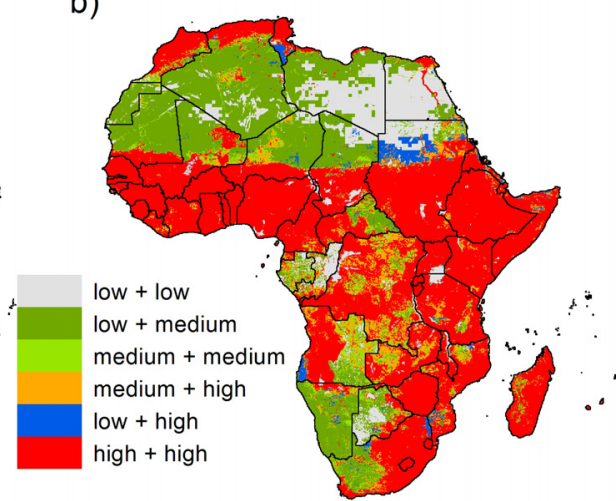

Figure 4: Hotspots of FC and BOD loadings separated into high, medium and low loading classes; a) for the reference year; b) for the model experiment.

\subsection{In-stream concentration hotspots}

In order to identify hotspots of in-stream concentrations a classification system of low, medium and high FC and BOD concentrations was prepared analogue to the loading hotspots (tab. 2). The classification is based on guidelines on water quality, e.g. for FC concentrations in class low are water usable for drinking or primary contact activities such as swimming, class medium contains water usable for irrigation and class high contains the maximal tolerable class and concentrations which exceed all guidelines.

The generation of maps of in-stream concentration hotspots follows the same methodology as described for the loading hotspots (section 3.2). Figure 5a) indicates the hotspots of in-stream concentrations, i.e. regions where $\mathrm{FC}$ and 
Table 2: Classification of high, medium and low in-stream concentrations for $\mathrm{FC}$ in $\mathrm{cfu} / 100 \mathrm{ml}$ and BOD in $\mathrm{mg} \mathrm{L}^{-1}$.

\begin{tabular}{lccc}
\hline Substance & Low & Medium & High \\
\hline FC & $0-200$ & $200-1000$ & $>1000$ \\
BOD & $0-2.5$ & $2.5-10$ & $>10$ \\
\hline
\end{tabular}

BOD in-stream concentrations are high. One hotspot covers the coast line of Morocco, Algeria, and Tunisia and is in agreement with the loading hotspot. Further major hotspots are Ethiopia, the Lake Victoria region, and west of the Republic of South Africa. In the south of the Sahara concentrations are high for both substances due to low river discharge by means of low dilution capacity. Furthermore, the Nile delta is a hotspot region, too, but not the upstream Nile catchment which is a $\mathrm{LH}$ region, because for all $\mathrm{LH}$ regions $\mathrm{FC}$ in-stream concentrations are high while BOD in-stream concentrations are low. This is contrary to the loadings where in class LH in-stream concentrations of BOD were higher than FC in-stream concentrations. FC concentrations dominate because the impact of loadings is greater on the in-stream concentration than the river discharge. Most Nigerian rivers are in category LH and also in Angola the in-stream concentrations of FC and BOD are opposed. In category $\mathrm{HH}$ are $12 \%$ of the displayed rivers, thus $8 \%$ of the total African population is directly affected (in river grid cells) which corresponds to $41 \%$ of the population living alongside large rivers. However, it can be assumed that not only the population on the grid cells of the river stretches is affected by the water quality degradation but also those of adjacent grid cells. In category $\mathrm{HH}$ and $\mathrm{MH}$ are $22 \%$ of the displayed rivers of the African continent. About $13 \%$ of the total African population lives in regions falling in this category. This is equivalent to $59 \%$ of the population living alongside large rivers. Overall, about $50 \%$ of the population living at large rivers are at risk of water pollution indicated by high in-stream concentration hotspots as used in this study. The number of population at risk is therefore significantly lower compared to the loading hotspots (around 90\%). This is due to the dilution capacity which reduces the effect of high loadings, i.e. in-stream concentrations are low when the dilution is high (e.g. Nile catchment). Our model results show that a high load does not necessarily leads to high instream concentrations. Nevertheless, a degradation of water quality can be expected in $50 \%$ of the large African rivers, which in turn poses a risk to human health and ecosystems.

In the model experiment assuming the total population is connected to sewage treatment plants but treatment levels stay the same as for the reference year, FC and BOD in-stream concentrations are likely to be much higher. This results in an increase of hotpot areas as well as in the number of hotspots (figure 5b)). Hotspots of in-stream concentrations are in Eastern Africa and the east of the Republic of South Africa, the coastline of Morocco, Algeria and Tunisia and parts of Western Africa. Other parts of Western Africa and Middle Africa feature high FC and low BOD in-stream concentrations (category LH). The majority of Middle Africa and the Sahara are in category LL, i.e. regions with a low risk 
of river pollution. In category $\mathrm{HH}$ is $27 \%$ of the total African land area, which is twice as much as under the reference conditions, and thus corresponds to $13 \%$ of the total population (59\% of the population living at large rivers). About $45 \%$ of the land area is attributed to category $\mathrm{HH}$ and $\mathrm{MH}$ where $17 \%$ of the total population is directly affected (76\% of the population living at large rivers). Finally, under these assumptions around $70 \%$ of the population living at large rivers are at risk because of degraded water quality.

a)

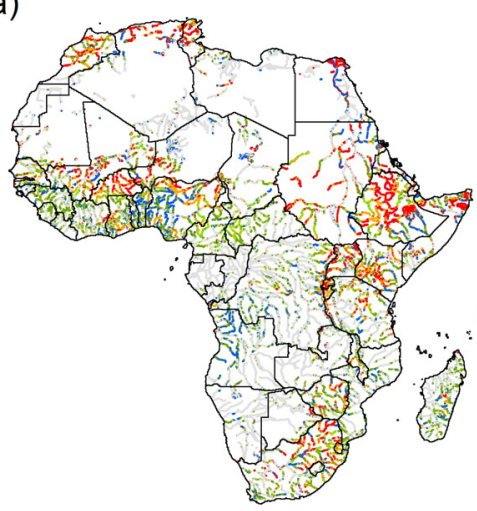

b)

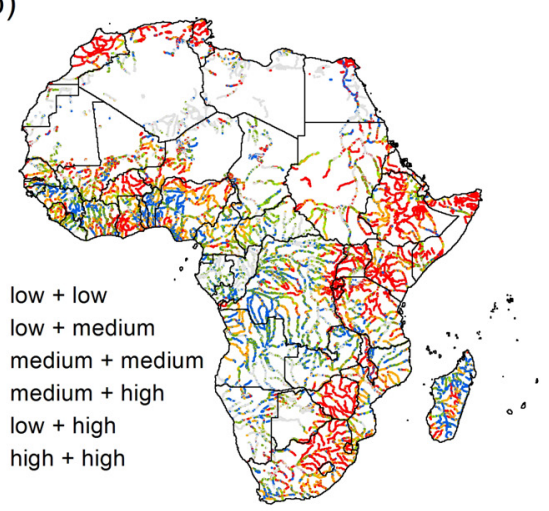

Figure 5: Hotspots FC and BOD in-stream concentrations separated into high, medium and low concentration classes in 2010; a) for the reference year; b) for the model experiment.

\section{Conclusions}

The scope of this paper was to identify hotspots of FC and BOD loadings and instream concentration in Africa posing a risk for human and ecosystem health. We presented model results of FC and BOD loadings and in-stream concentration for the whole African continent for the years 2010 and 2009, respectively. All simulations were carried-out with the large-scale water quality model WorldQual, a model imbedded in the WaterGAP3 modelling framework.

Africa is an extremely data scarce region, especially in terms of measured data related to water quality. Therefore, where no other information exists, modelled information gives insight on the current water quality status. Hotspot regions, hence regions with high loadings and in-stream concentrations could be identified at the coastline of Morocco, Algeria and Tunisia, Eastern Africa, parts of Western Africa, particularly Nigeria, and the east of the Republic of South Africa. These regions are characterised by high population density and/or increased human activities, because we identified the domestic sector (FC) and manure application (BOD) to be the main source of total loads. Regions where loadings and in-stream concentrations are low are located in Middle Africa and North Africa (Sahara). Additionally, we performed a model experiment where 
the total population would be connected to sewage systems but no more treatment than in the reference year exists. In consequence of this model experiment, management strategies to improve or maintain good water quality in rivers should consider proper wastewater treatment or at least its functional capability. Otherwise only the risk of direct contact with faeces is reduced, but downstream abstractors who get in direct contact by e.g. using the water for washing, swimming and drinking have an increased risk. This situation will become of greater importance in the future under the projection of population growth and increasing urbanization, which will put additional pressure on existing sanitation systems and moreover on water quality.

Further research can improve the modelling of manure application by integration of surface runoff retention. In addition, the simulation exercise can be applied to other continents such as South America and Asia and further substances like total nitrogen and total phosphorus.

\section{Acknowledgements}

The authors gratefully acknowledge the South African Department of Water Affairs and the UNEP GEMS/Water Programme for the provision of faecal coliform bacteria and biological oxygen demand in-stream concentrations measured in rivers of the Republic of South Africa and Morocco, respectively. This manuscript is part of the work conducted within the "Assessment of World Water Quality to Meet the Global Water Quality Challenge".

\section{References}

[1] United Nations. 55/2. United Nations Millennium Declaration: Resolution adopted by the General Assembly, 2000 [cited 2014 Feb 5]. Available from: URL:http://www.un.org/millennium/declaration/ares552e.htm.

[2] United Nations. UN Millennium Project: Goals, targets and indicators, 2006. Available from: URL: http://www.unmillenniumproject.org /goals/gti.htm.

[3] United Nations. The Millennium Development Goals Report 2011. New York, 2011.

[4] Banerjee S, Morella E. Africa's Water and Sanitation Infrastructure: Access, Affordability, and Alternatives. Washington, DC: World Bank, 2011.

[5] United Nations. World Urbanization Prospects The 2011 Revision. New York: Department of Economic and Social Affairs ST/ESA/SER.A/322, 2012.

[6] African Development Bank Group. Briefing Note for AfDB's Long-Term Strategy - Africa's Demographic Trends, Briefing Note 4: Africa's Demographic Trends, 2012.

[7] World Bank. Growth and Development in Emerging Markets and other Developing Countries: Group of Twenty. Seoul, Korea, G20 Growth Framework and Mutual Assessment Process, 2010. 
[8] European Commission. 76/160/EEC, 1975.

[9] Anderson K, Davidson P. Drinking Water \& Recreational Water Quality: Microbiological Criteria: The College of Agricultural and Life Sciences CIS 1069, 1997.

[10] Malve O, Tattari S, Riihimäki J, Jaakkola E, Voß A, Williams R et al. Estimation of agricultural non-point load at the European scale. Hydrological Processes, 26(16):2385-94, 2012.

[11] Reder K, Bärlund I, Voß A, Kynast E, Williams R, Malve O et al. European scenario studies on future in-stream nutrient concentrations. Transactions of the ASABE, 56(6):1407-17, 2013.

[12] Reder K, Flörke M, Alcamo J. Modeling historical fecal coliform loadings to large European rivers and resulting in-stream concentrations [submitted], 2014.

[13] Voß A, Alcamo J, Bärlund I, Voß F, Kynast E, Williams R et al. Continental scale modeling of in-stream river water quality: A report on methodology, test runs, and scenario application. Hydrological Processes, 26(16):2370-84, 2012.

[14] Williams R, Keller V, Voß A, Bärlund I, Malve O, Riihimäki J et al. Assessment of current water pollution loads in Europe: Estimation of gridded loads for use in global water quality models. Hydrological Processes, 26(16):2395-410, 2012.

[15] Lehner B, Verdin K, Jarvis. A. New global hydrography derived from spaceborne elevation data. Eos, Transactions, 89(10), 2008.

[16] Thomann R, Mueller J. Principles of Surface Water Quality Modeling and Control. Harper Collins Publishers, 1987.

[17] Verzano K. Climate change impacts on flood related hydrological processes: Further development and application of a global scale hydrological model [PhD thesis]. Kassel, Germany: University of Kassel, 2009.

[18] Alcamo J, Döll P, Heinrichs T, Kaspar F, Lehner B, Rösch T et al. Development and testing of the WaterGAP 2 global model of water use and availability. Hydrological Sciences Journal, 48(3):317-37, 2003.

[19] Döll P, Kaspar F, Lehner B. A global hydrological model for deriving water availability indicators: model tuning and validation. Journal of Hydrology, 270:105-34, 2003.

[20] Beek T aus der, Flörke M, Lapola D, Schaldach R, Voß F, Teichert E. Modelling historical and current irrigation water demand on the continental scale: Europe. Advances in Geoscience and Remote Sensing, 27:79-85, 2010.

[21] Flörke M, Kynast E, Bärlund I, Eisner S, Wimmer F, Alcamo J. Domestic and industrial water uses of the past 60 years as a mirror of socioeconomic development: A global simulation study. Global Environmental Change-Human and Policy Dimensions, 23(1):144-56, 2013.

[22] JMP Country Files (1980-2011), 2013. Available from: URL: http://www.wssinfo.org/documents-links/documents/?tx_display controller [type] $=$ country_files. 